\title{
RELATIONSHIPS BETWEEN EXPLICIT AND IMPLICIT SELF-ESTEEM AND THE NEED FOR SOCIAL APPROVAL AND NARCISSISM IN PERSONS HOLDING MANAGERIAL POSITIONS
}

\begin{abstract}
Self-esteem determines the well-being of an individual; it is related to health and physical conditions, and consequently, it influences a person's behavior, decision-making and social functioning. It has been the subject of research for many years, and yet no reliable measurement tools have been developed, especially in relation to implicit self-esteem. It is assumed that explicit and implicit self-esteem are different manifestations of attitudes towards oneself and do not have to be compatible with each other (they are poorly correlated; as a rule, the correlation does not exceed 0.25 ). For people in managerial positions in an organization, self-esteem can be a decisive factor in achievement. In this study, it was, therefore, assumed that managers have a positive relationship between explicit self-esteem and variables implicitly related to self-esteem, that is, the level of the need for social approval and the level of narcissism. The research was carried out in two groups: managers (people at the highest, middle or lower levels in the organizational structure, managing a team of people) and employees who do not play managerial roles (people who perform a scope of duties that do not include responsibility for the results of other people's work). The results of this study showed that for managers, the relationship between the scale of the need for social approval and narcissism was particularly important for the leadership and self-sufficiency scales; these are the scales that indicate the most desirable aspects of narcissism for managers. This correlation was not found in the control group. The tools for measuring implicit self-esteem were also used to compare the results for both of its aspects.
\end{abstract}

Keywords: management and leadership, explicit and implicit self-esteem, social approval, narcissism.

\section{INTRODUCTION}

Self-esteem, its height, and especially its stability, are significantly related to the manager's well-being, their behavior, functioning in society and in an organization, responsibility and propensity to risk, decision-making, and therefore, in a broader perspective, with the quality of their management. Individuals with a positive attitude towards their own self are assessed by the environment as having the characteristics of a group leader. They are willing to express their views, often take part in discussions, are

\footnotetext{
${ }^{1}$ Agata Gierczak, PhD, Faculty of Management, Rzeszow University of Technology; e-mail:
} agatag@prz.edu.pl. ORCID: 0000000284020919. 
convinced of their own interpersonal skills, the possibility of influencing other people, providing them with support, and that they are socially attractive and liked by others (which does not have to be confirmed in reality). They are generally characterized by a greater sense of happiness, life satisfaction and an optimistic outlook for the future. On the other hand, people with low self-esteem have a feeling of less approval from the environment, less support, which is associated with the fear of rejection. They are more depressive and experience more psychosomatic symptoms. Their attitude towards themselves is associated with experiencing shame and embarrassment. The level of self-esteem is related to setting higher goals and beliefs about the possibility of meeting them (Baumeister et al., 2003; Dzwonkowska, Lachowicz-Tabaczek, and Łaguna, 2008).

Research showed that the implicit self-esteem could reduce the threat to the self in situations where overall self-esteem was at risk. It was then discovered that it acted as a buffer (Fujii et al., 2014; Greenwald and Farnham, 2000; Inagaki (Fujii), Oura, Matsuo, Shima, Fukui, 2017). High implicit self-esteem can reduce the occurrence of negative emotions and moods. The implicit self-esteem most often plays the role of a moderator of behaviors and expectations, "cooperating" in this respect with the explicit self-esteem.

Methods of measuring self-esteem, especially implicit ones, are a big problem for researchers as they mainly focus on its explicit aspects and are usually self-report tools, which, especially in the group of managers, may trigger self-presentation mechanisms that distort the indications of these tools. Self-esteem researchers argue intensely whether the explicit and implicit self-esteem measures investigate the same theoretical construct (Olson, Fazio, Hermann, 2007) or whether they apply to two different constructs (Koole, Dijsterhuis, and van Knippenberg, 2001; Wilson, Lindsey, Schooler, 2000), or they agree that the measurement of the implicit self-esteem is essential in diagnosing it. Therefore, in recent years, an intense search for new and effective methods of measurement has been carried out and a lot of significant results have been accumulated.

It is assumed that low implicit self-esteem is at the root of volatile self-esteem. People with high explicit and low implicit self-esteem show a higher level of narcissism, favor their own group more, and use more defense mechanisms to maintain a positive self-image (Bosson, Brown, Zeigler-Hill, Swann, 2002). Narcissistic managers often associate selfimage and self-esteem with the admiration and respect of others, which is why they can be expected to have a high level of need for social approval. They are sensitive to criticism or failure; this sensitivity can lead to withdrawal from social interaction.

In this paper it was assumed that managers had a positive relationship between the explicit self-esteem and variables implicitly associated with self-esteem, i.e. with the level of social approval and the level of narcissism; the higher the explicit (global) self-esteem, the higher the level of the need for social approval and the higher the explicit (global) self-esteem, the higher the level of narcissism.

\section{LITERATURE REVIEW}

The relationships between narcissism and self-esteem have been the subject of ongoing research, and yet they are still considered unclear. Most of these studies look at narcissistic greatness, neglecting the vulnerable form of narcissism that could be accessed using a measure of implicit self-esteem. Research shows that the relationship between narcissistic traits and the explicit self-esteem is not unequivocal (Di Pierro, Mattavelli, Gallucci, 2016). Patterns of association between narcissistic traits and the explicit self-esteem may vary, 
depending on the phenotypic manifestations of narcissism. In the DSM-5 classification of personality disorders (American Psychiatric Association, 2013), variable and vulnerable self-esteem is one of the typical features of narcissistic pathology. Kernis (2003) suggests that narcissism is associated with fragile self-esteem, and that this fragility may be due to instability in self-esteem, conditional self-esteem, or a discrepancy between the explicit and implicit self-esteem.

Inconsistent findings in research on narcissism and its relationship with the explicit and implicit self-esteem may have been a consequence of the lack of general consensus regarding the definition of narcissism (Bosson and Prewitt-Freilino, 2007). An attempt was made to describe narcissism as two separate dimensions of personality - adaptive and pathological narcissism (Miller and Campbell, 2008; Pincus and Lukowitsky, 2010). Basically, narcissism refers to an ability to maintain a relatively positive self-image through a variety of affect self-regulation and environmental regulation processes (Pincus et al., 2009). On the one hand, adaptive narcissism reflects an emotion-resistant, extroverted form of narcissism - people with adaptive narcissistic traits are able to maintain consistency by extracting affirmative responses from the environment and are able to access inner resources in the face of disappointment - on the other hand, pathological narcissism can be described through voluminous and sensitive behaviors, including impaired regulatory abilities and a strong need for self-esteem and admiration that stimulate a person to seek experience and self-improvement (Pincus and Lukowitsky, 2010; Roche et al., 2003; Pincus et al., 2014). Narcissistic omnipotence is expressed in fantasizing of unlimited power, superiority and perfection, while disregarding the needs and feelings of others. In contrast to this attitude, narcissistic vulnerability involves consciously experiencing helplessness, emptiness, jealousy, shame, anger, and avoidance of interpersonal relationships due to fear of rejection and criticism (Rovik, 2001; Aktar, 2003; Dickinson, Pincus, 2003; Ronningstam, 2005; Pincus et al., 2014). According to Roche (2013), an individual may have a constellation of normal and pathological regulatory mechanisms that are used under various conditions to deal with disappointments and threats to their own self. Numerous studies show that both types of narcissism moderately correlate (Wright et al., 2010; Fossati et al., 2014; Jaksic et al., 2014; Krusemark et al., 2015). Grandiose and vulnerable narcissisms showed different patterns of association with self-esteem in non-clinical trials (Pincus et al., 2009; Maxwell et al., 2011; Roche et al., 2013). All studies show unequivocally that vulnerable narcissism can predict a low level of explicit self-esteem. Narcissistic traits may be associated with the explicit self-esteem in various ways and that people with pathological (grandiose) narcissism traits do not always declare high selfesteem. The researchers Di Pierro, Mattavelli, and Gallucci (2016) asked why some people with high levels of narcissistic greatness declared overrated self-esteem, while others do not. In response, it was hypothesized that external conditions, such as contact with others, might influence self-presentation in people with the features of size narcissism. Therefore, this is an assumption that fulfilling the role of a manager may be a circumstance that exacerbates the features of pathological narcissism. Brunell and Fisher (2014) investigated that confrontation with other people during the assessment procedure did not take into account the bias in self-presentation reactions in people with high narcissism. However, according to one group of researchers (Jordan et al., 2003; Zeigler-Hill, 2006; Campbell et al., 2007), they may have positive or negative implicit self-perceptions, according to others (Vater et al., 2013; Marissen et al., 2016), narcissistic people do not differ in the level of implicit self-esteem compared to control groups of non-narcissistic people. 
In recent years, researchers have become increasingly interested in narcissistic leadership (Owens, Walker, Waldman, 2015). The question arises whether narcissistic personality traits predispose people to perform managerial roles in organizations, or whether one can become a narcissist while performing these functions. Chinese researchers noted (Xiao, Liu, Zhou, Chen, 2018) that most of the research focused on the narcissistic traits of the leaders under the survey, but did not take into account the influence of time on the narcissistic manager's relationship with employees (Roberts, Arthur, Woodman, Akehurst, 2016). It was shown that narcissistic leaders did not care about the demands of their subordinates and often cheated, diminished the role of employees, and even harassed and hurt them (Rosenthal and Pittinsky, 2006), thus destroying social relationships. Narcissistic leaders also take advantage of others, caring only for their own needs, sometimes going so far as to engage in negative behavior and hurting others.

Empirical research into the relationship between narcissism and self-esteem was largely dominated by the "mask model" that postulates that narcissists' positive views mask a deepseated sense of inferiority and inadequacy (Kernberg, 1975; Kohut, Wolf, 1986; Emmons, 1987). According to this model people with a high level of narcissistic traits should reveal a very high level of explicit self-esteem combined with a relatively low level of implicit self-esteem. Despite the advantage of the mask model, an empirical study of the relationship between narcissism, explicit self-esteem, and implicit self-esteem led to conflicting conclusions. Much early research focused on the idea of a positive relationship between explicit self-esteem and narcissism (Jordan et al., 2003; Brown and Zeigler-Hill, 2004; Zeigler-Hill, 2006; Cain et al., 2008; Rosenthal and Hooley, 2010; Brummelman et al., 2016), as well as self-improvement tendencies (Bosson et al., 2003), which are hallmarks of narcissism. In some studies, it was possible to confirm the mask model, i.e. the combination of high explicit and low implicit self-esteem predicted narcissistic features (Jordan et al., 2003; Zeigler-Hill, 2006; Boldero, 2007 Unpublished, after: Di Pierro, Mattavelli, Gallucci, 2016). However, a meta-analysis of this type of research (Bosson et al., 2008) did not provide empirical support for such results. More recent studies failed to replicate previous results, showing a negligible interaction between the implicit and explicit self-esteem in predicting narcissistic traits (Campbell et al., 2007; Gregg and Sedikides, 2010), or even an opposite association pattern (Vater et al., 2013).

Much research on the relationship of narcissism with self-esteem is carried out using the Narcissistic Personality Inventory (NPI, Raskin, Hall, 1979), which measures the main adaptive characteristics of grandiose narcissism (Watson et al., 2005-2006; Cain et al., 2008; Rosenthal et al. Hooley, 2010). The measurement takes place in four dimensions, two of which may show a beneficial relationship with the managerial function - the Leadership Scale (referring to the belief in one's own high leadership abilities and one's own influence on others) and the Self-Sufficiency Scale (belief in one's own independence, individualism, high competences and success), while the other two certainly do not - the Vanity Scale (approval of one's own corporeality and aestheticism) and the Scale of Demanding Admiration (reflects the need for meaning, admiration, being noticed, complimented, as well as famous and - what is marked in the name of the scale - contains an element of claiming "demand"). This tool was also used in the research presented in this paper. Using them, researchers showed that the NPI scale partially overlapped with the measures of self-esteem (Brown and Zeigler-Hill, 2004; Rosenthal and Hooley, 2010), which may explain the positive links between narcissism and explicit self-esteem in the research. 


\section{MATERIALS AND METHODS}

The field study was carried out individually. Standardized questionnaires were used to measure the variables:

- M. Rosenberg's SES questionnaire, the global self-esteem scale in the Polish adaptation by Łaguna, Lachowicz-Tabaczek and Dzwonkowska (2007), the scale consisting of 10 items measures the general level of self-esteem;

- Social approval questionnaire (KAS, Drwal, Wilczyńska 1980), Social Desire Scale, developed according to various scales of lying and social acceptance;

- The NPI Narcissistic Personality Inventory (Raskin and Hall, 1979) in the Polish adaptation by Brzezińska and Drat-Ruszczak (2000) - the measurement takes place in 4 dimensions: Leadership Scale (referring to the belief in one's own high leadership abilities and one's own influence on others), The Self-Sufficiency Scale (belief in one's own independence, individualism, high competences and success), the Vanity Scale (approval of one's own body and aestheticism) and the Demanding Admiration Scale (reflects the need for meaning, admiration, being noticed, complimented, and also famous and - which was noted in the name of the scale - it contains an element of claiming "demand").

The tools for measuring implicit self-esteem were also used:

- Measurement of the size of the signature (initials) (Zweigenhaft, Marlowe 1973),

- Gebauer name preference test (Gebauer et al., 2008), in which the degree of first and last name preference is an indicator of implicit self-esteem,

- IAT - Implicit Association Test (Greenwald, McGhee, Schwartz, 1998), the best known method of testing implicit attitudes (including implicit self-esteem) using the affective association method in the process of categorizing objects on a computer screen. The use of the IAT requires a selection of stimuli. The incentives for the test were selected in a pilot study in a group of 500 people. They were asked to choose the words which, in their opinion, could be best and most accurately assigned to the categories: 1. Me and non-me, 2. Pleasant words, 3. Unpleasant words. Earlier, in a group of 40 people, suggestions of stimuli were submitted which, according to the respondents, best represent the three above categories. Six stimuli were selected in each of them: 1. describing I and non-I: character, relationships, body, value, feelings and voice; 2. pleasant words: happiness, love, joy, peace, satisfaction and success; 3. unpleasant words: pain, disease, death, fear, war and sadness.

The purpose of using so many methods of investigating the implicit self-esteem was to estimate it as correctly as possible.

The selection of people for the study was carried out using the snowball method, consisting in recruiting participants by other participants. In order to minimize the researcher's control over the sample, the study was carried out in several places, extending the selection of units beyond economic entities also to administrative units and educational organizations. 83 people $(\mathrm{N}=83)$ participated in the study, including 41 managers and 42 non-managerial employees $(\mathrm{M}=43.9$; $\mathrm{SD}=9.8)$; 40 women and $43 \mathrm{men}$. In the group of managers, the mean age was $\mathrm{M}=47.1(\mathrm{SD}=8.7)$, and in the group of regular employees, $\mathrm{M}=41.0(\mathrm{SD}=9.8)$. A manager is defined as a person at the highest, medium or lower levels in the organizational structure who manages a team of people. Employees who did not perform the function of a manager were considered to be persons who worked in the 
performance of a scope of duties that did not include responsibility for the results of other people's work.

Explained variables: narcissism, the need for social approval and the group of respondents (managers vs. non-managers). Explanatory variables: explicit global selfesteem, implicit self-esteem.

Reliability determined by the Cronbach's $\alpha$ index are as follows:

the reliability of M. Rosenberg's SES questionnaire for measuring the explicit global self-esteem was $\alpha=0.78$, which is a fully acceptable value; the reliability of the NPI questionnaire for measuring the level of narcissism was $\alpha=0.96$, which is a very high value. All subscales of the narcissism scale achieved a high index: the reliability of the sub-scale. The admiration of the narcissism scale in the study was $\alpha=0.90$, the reliability of the Leader subscale of the narcissism scale in the study was $\alpha=0.93$, the reliability of the subscale Void of the narcissism scale was $\alpha=0.83$ in the study, the reliability of the Self-Sufficient subscale of the narcissism scale in the study was $\alpha=0.81$.

\section{RESULTS}

In order to verify the assumptions adopted, an r-Pearson correlation analysis was performed. The explicit self-esteem was measured with the Rosenberg SES Scale and for the implicit self-esteem the IAT effect, signature size (initials) and name and surname preference (Gebauer Test) were applied. The relationship of these indicators with the level of the need for social approval was shown. The survey was carried out on the entire sample of respondents (managers and people not performing managerial functions). The results are presented in Table 1.

Table 1. Correlations between variables related to self-esteem and the level of the need for social approval

\begin{tabular}{|l|c|c|c|c|}
\hline & $\begin{array}{c}\text { SES } \\
\text { Rosenberg }\end{array}$ & IAT effect & Signature & $\begin{array}{c}\text { Implicit (name } \\
\text { and surname) }\end{array}$ \\
\hline SES Rosenberg & & & & \\
\hline IAT effect & -.048 & & & \\
\hline Signature & .211 & .120 & & \\
\hline $\begin{array}{l}\text { Implicit (name and } \\
\text { surname) }\end{array}$ & $\mathbf{. 5 2 6 ^ { * * }}$ & .066 & .133 & .090 \\
\hline $\begin{array}{l}\text { The need for social } \\
\text { approval }\end{array}$ & .231 & -.147 & .191 & \\
\hline
\end{tabular}

* Correlation significant at the level of 0.05 (two-sided)

** Correlation significant at the level of 0.01 (two-sided)

Source: own study.

Among all self-esteem indicators, a strong statistically relevant positive relationship was observed between the measure of implicit self-esteem, which is the first and last name preference, and explicit self-esteem measured with Rosenberg's SES test $r=0.53 ; p<0.01$.

The remaining relationships turned out to be statistically insignificant. 
Then, correlations between the narcissism scales and the scale of the need for social approval were shown also in the entire sample of respondents $(\mathrm{N}=83)$ (Table 2).

Table 2. Correlations of narcissism scales with the level of the need for social approval in the entire group of respondents

\begin{tabular}{|l|c|c|c|c|c|}
\hline & $\begin{array}{c}\text { Narcissism } \\
\text { total }\end{array}$ & Admiration & Vain & Leader & Self-sufficient \\
\hline $\begin{array}{l}\text { The need for } \\
\text { social approval }\end{array}$ & .179 & .122 & .037 & .209 & .229 \\
\hline
\end{tabular}

* Correlation significant at the level of 0.05 (two-sided)

Source: own study.

It turns out that the need for social approval does not correlate with any of the narcissism scales. However, the result of the analysis changes in the next step, when we conduct the survey only in the group of managers (Table 3).

Tabela 3. Correlations of the level of the need for social approval with the scales of narcissism and overt self-esteem in the group of managers

\begin{tabular}{|l|c|c|c|c|c|c|}
\hline & $\begin{array}{c}\text { Narcissism } \\
\text { total }\end{array}$ & Admiration & Vain & Leader & Self-sufficient & $\begin{array}{c}\text { SES } \\
\text { Rosenberg }\end{array}$ \\
\hline $\begin{array}{l}\text { The need for } \\
\text { social approval }\end{array}$ & $.298 \#$ & .221 & .061 & $.363^{*}$ & $.426^{* *}$ & $.245 \#$ \\
\hline
\end{tabular}

* Correlation significant at the level of 0.05 (two-sided)

** Correlation significant at the level of 0.01 (two-sided)

\# Correlation significant at the level of 0.05 (one-sided)

Source: own study.

Among managers there is a significant positive relationship between the level of the need for social approval and explicit self-esteem and the level of narcissism, although significance is obtained in the one-sided test. Thus, the hypothesis assuming the existence of a correlation of the level of social approval and narcissism with the explicit self-esteem has been positively verified.

The relationship between the need for social approval and narcissism is particularly important for the Leader Scale $(r=0.36 ; p \leq 0.05)$ and the Self-Sufficient Scale $(r=0.42$; $\mathrm{p} \leq 0.01$ ), i.e. for those scales that indicate the most desirable narcissism aspects for managers. This may suggest that managers also make some form of self-presentation when filling in questionnaires. Such correlations with the need for social approval were not found in the group of subordinate employees.

Another hypothesis, which says that managers have a higher level of need for social approval than employees who do not perform managerial functions, was put forward. A particularly high level of this need occurs in managers with high explicit and low implicit self-esteem. For this purpose, an analysis of variance was performed for the variable "need for social approval" in the $2 \times 2$ system (group of respondents x gender). The analysis did not show any significant effects, so on this basis it cannot be said that the level of social approval of managers is higher than in the control group. In order to verify this hypothesis 
in terms of the specificity of the group of managers with high vulnerable self-esteem, three simultaneous regression analyzes were carried out in the group of managers for the variable explained the level of the need for social approval, taking into account each of the measures of implicit self-esteem used as predictors. First, both explicit and implicit self-esteem indicators were standardized, then product products representing the interaction between the explicit and implicit self-esteem indicators were created (Aiken and West, 1991; Jordan et al., 2003). In the regression analyzes, explicit and implicit self-esteem and their product product were introduced as predictors. In regression analysis, where the criterion was the level of the need for social approval, and the predictors were explicit self-esteem, implicit self-esteem measured with the IAT test and the product (Cartesian product) of the latter two, neither the model significance nor the interaction effect of self-esteems in explaining the criterion were obtained. A similar situation occurred when liking one's name and surname was introduced as implicit self-esteem, and also when the implicit self-esteem was represented by the size of one's own signature. Thus, this hypothesis has not been positively verified.

The assumption that managers have a higher level of narcissism than people who do not perform managerial functions, especially on the Leadership and Self-sufficiency scales, was made in the research. In order to verify this hypothesis, an analysis of variance was performed for the dependent variable level of narcissism in a mixed system (4) x $2 \times 2$ with an intra-subject factor, narcissism scale, and inter-subject factors, group and gender. The analysis showed the following effects:

1. main effect of the narcissism scale $F(3.77)=56.49 ; p \leq 0.001 ; \eta^{2}=0.69$

2. group $F$ main effect $(1.79)=3.55 ; p \leq 0.05$ (one-tailed test); $\eta^{2}=0.04$

3 . interaction effect of the narcissism scale and group $F(3.77)=7.23 ; p \leq 0.001$; $\eta^{2}=0.22$

The interaction effect (along with both main effects) is shown in figure 1.

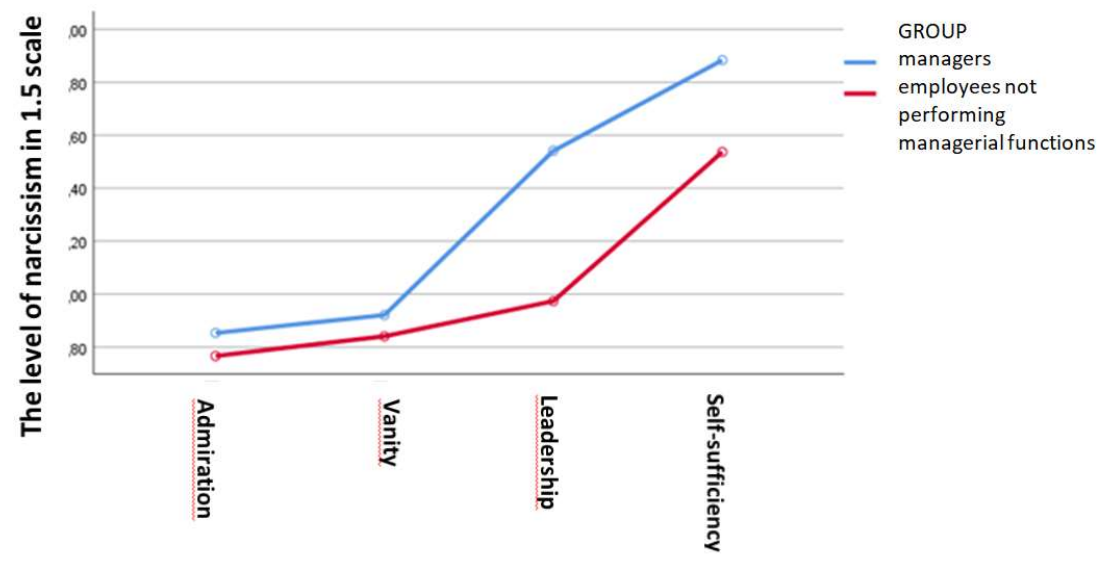

Narcissism scale

Figure 1. The level of narcissism depending on its scale and the group of respondents

Source: own study. 
The groups do not differ on the narcissism scales, Admiration Demand and Vanity, while on the Leadership scale, managers score significantly higher than non-managerial employees: $\mathrm{F}(1.79)=11.38 ; \mathrm{p} \leq 0.001 ; \eta^{2}=0.13$, similarly, on the Self-sufficiency scale, managers achieve a significantly higher score than subordinate employees: $F(1.79)=7.30$; $\mathrm{p} \leq 0.01 ; \eta^{2}=0.09$. So the hypothesis was confirmed.

\section{CONCLUSIONS}

The research confirmed the hypothesis concerning the level of narcissism in managers; it was significantly higher in this group than in the subordinate employees, and it concerned mainly the Leadership and Self-sufficiency narcissism scales, i.e. those that may be beneficial in the manager's work. In fact, on the Demanding Admiration and Vanity scales, the differences between the groups did not reach the significance level. Narcissism in managers is significantly and positively correlated with the scale of the need for social approval and the explicit self-esteem. However, the hypothesis that managers have a higher level of need for social approval than employees who do not perform managerial functions was not confirmed, and that a particularly high level of this need occurs in managers with high explicit and low implicit self-esteem. Perhaps this is due to the fact that the implicit self-esteem measures are still very imperfect. Therefore, they should be improved in order to more accurately diagnose, in particular, conflicts arising from the inconsistency of both assessments.

\section{REFERENCES}

Aiken, L. S., West, S. G. (1991). Multiple Regression: Testing and interpreting interactions. Newbury Park, CA: Sage.

Baumeister, R. F., Campbell, J. D., Krueger, J. I., Vohs, K. D. (2003). Does high self-esteem cause better performance, interpersonal success, happiness, or healthier lifestyles?, "Psychological Science in the Public Interest", 4(1).

Bosson J. K., Brown R. P., Zeigler-Hill V., Swann W. B., (2003). Self-Enhancement Tendencies Among People With High Explicit Self-Esteem: The Moderating Role of Implicit Self-Esteem. "Self and Identity", Vol. 2, issue 3.

Bosson, J. K. et al. (2008). Untangling the links between narcissism and self-esteem: A theoretical and empirical review. "Social and Personality Psychology Compass" 2(3).

Brown, R. P., Zeigler-Hill, V., (2004). Narcissism and the non-equivalence of self-esteem measures: A matter of dominance?, "Journal of Research in Personality”, Vol. 38, issue 6.

Brummelman, E., Thomaes, S., Sedikides, C. (2016). Separating narcissism from self-esteem, Vol. 25, issue 1. Access on the internet: journals.sagepub.com.

Brunell, A. B., Fisher, T. D. (2014). Using the bogus pipeline to investigate grandiose narcissism. "Journal of Experimental Social Psychology", Vol. 55.

Brzezińska, R., Drat-Ruszczak, Z. (2000). Struktura narcyzmu w polskiej adaptacji kwestionariusza NPI Ruskina i Halla. „Czasopismo Psychologiczne”, 6.

Cain, N. M., Pincus, A. L., Ansell, E. B. (2008). Narcissism at the crossroads. Phenotypic description of pathological narcissism across clinical theory, social/personality psychology, and psychiatric diagnosis. "Clinical Psychology Review”, Vol. 28, 4.

Campbell, W. K., Bosson, J. K., Goheen, T. W., Lakey, C. E., Kernis, M. H. (2007). Do narcissists dislike themselves ,, deep down inside”?, "Psychological Science”, 8. 
Dickinson, K. A., Pincus, A. L. (2005). Interpersonal analysis of grandiose and vulnerable narcissism. "Journal of Personality Disorders", Vol. 17, No. 3

Di Pierro, R., Mattavelli, S., Gallucci, M. (2016). Narcissistic traits and explicit self-esteem: The moderating role of implicit self-view. "Frontiers in Psychology", 7.

Drwal, R. Ł., Wilczyńska, J. T. (1980). Opracowanie kwestionariusza aprobaty społecznej. „Przegląd Psychologiczny”, 23(3).

Dziwota, K., Dudek A., Szpak, A., Ludwikowska, K. (2016). Value preferences in individuals with low and high self-esteem. "Current Problems of Psychiatry".

Dzwonkowska, I., Lachowicz-Tabaczek, K., Laguna, M. (2008). Samoocena i jej pomiar. Polska adaptacja skali SES M. Rosenberga. Podręcznik. Warszawa: Pracownia Testów Psychologicznych PTP.

Emmons, R. A. (1987). Narcissism: Theory and measurement. "Journal of Personality and Social Psychology", 52(1).

Fossati, A., Feeney, J., Pincus, A., Borroni, S., Maffei, C. (2015). The structure of pathological narcissism and its relationships with adult attachment styles: A study of Italian nonclinical and clinical adult participants. "Psychoanalytic Psychology", 32(3).

Gebauer, J. E., Riketta, M., Broemer Ph., Maio G. R., (2008). How much do you like your name? An implicit measure of global self-esteem. "Journal of Experimental Social Psychology, Elsevier", 44(5).

Golec de Zavala, A., Cichocka, A., Eidelson, R. Jayawickreme, N. (2009). Collective narcissism and its social consequences. "Journal of Personality and Social Psychology".

Greenwald, A. G., Farnham, S. D. (2000). Using the Implicit Association Test to measure self-esteem and self-concept. "Journal of Personality and Social Psychology", 79.

Greenwald, A. G., McGhee D. E., Schwartz, Jordan L. K. (1998). Measuring individual differences in implicite cognition: The Implicit Association Test. "Journal of Personality and Social Psychology", 74(6).

Gregg, A. P., Sedikides, C., (2010). Narcissistic fragility: rethinking its links to explicit and implicit self-esteem. "Self and Identity", 9:2. Access on the internet: www.psypress.com/sai

Jaksic, N., Goran, M., Ivezic, E., Wertag, A., Jokic-Begic, N., Pincus, A. L. (2014). The Pathological Narcissism Inventory (PNI) in a transitional post-war socjety: Factor structure and psychometric properties among Croatian University students. "Journal of Psychopathology and Behavioral Assessment”, 36(4).

Jordan, C. H., Spencer, S. J., Zanna, M. P. (2003). „I love me... I love me not:” Implicit selfesteem, explicit self-esteem, and defensiveness [In:] Spencer, S. J., Fein, S., Zanna, M.P., Olson J. M., eds, Motivated Social Perception: The Ontario Symposium. Vol. 9. Mahwah, NJ: Erlbaum.

Kernberg, O. (1975). Further contributions to the treatment of narcissistic personalities: A reply to the discussion by Paul H. Ornstein. "The International Journal of Psychoanalysis", 56.

Kernis, M.H. (2003). Toward a conceptualization of opimal self-esteem. "Psychol. Inq.", 14. DOI: $10.1207 / \mathrm{S} 15327965$ PLI1401 01.

Kohut, H., Wolf, E.S. (1986). „The disorders of self and their treatment: an outline” [In:] Morrison A. P., ed., Essential Papers on Narcissism, New York: New York University Press.

Koole, S. L., Dijksterhuis, A., van Knippenberg, A. (2001). What's in a name: Implicit self-esteem and the automatic self. "Journal of Personality and Social Psychology", 80(4). 
Krusemark, E., Lee, Ch., Newman, J. (2014). Narcissism demensions differentially moderate selective attention to evaluative stimuli in incarcerated offenders. "Personality Disorders: Theory, Research and Treatment", 6(1).

Łaguna, M., Lachowicz-Tabaczek K., Dzwonkowska I., (2007). Skala samooceny SES Morrisa Rosenberga - polska adaptacja metody. „, Psychologia społeczna”, t. 2 02(04).

Mandal, E. (2014). Beauty and social influence. Adonization and its correlates. "Polish Psychological Bulletin”.

Marissen, M. A. E., Brouver, M. E., Hiemstra, A. M. F., Deen, M. L., Franken, I. H. A. (2016). A masked negative self-esteem? Implicite and explicit self-esteem in patients with Narcissistic Personality Disorder. "Psychiatry Research", 30.

Miller, J. D., Campbell, W. K. (2008). Comparing clinical and social-personality conceptualizations of narcissism. "Journal of Personality". Access on the internet: www.onlinelibrary.wiley.com

Olson, M. A., Fazio, R. H., Hermann, A. D. (2007). Reporting tendencies underlie discrepancies between implicite and explicit measures of self-esteem. "Psychological Science", 18.

Ong, Ch. W., Roberts, R., Arthur, C. A., Woodman, T., Akehurst, S. (2016). The leadership is sinking: A temporal investigation of narcissistic leadership. "Journal of Personality", Vol. 84, issue 2.

Oura, S., Matsuo, K., Inagaki (Fujii), T., Shima, Y., Fukui, Y. (2017). Effects of manifestation and potential internal working models of attachment on depression. J-STAGE. "Emotional Psychology Research", Vol. 25(2017).

Owens, B. P., Walker, A. S., Waldman, D. (2015). Leader narcissism and follower outcomes: The counterbalancing effect of leader humility. "Journal of Applied Psychology", 100(4).

Pilch, I., Hyla, M. (2017). Narcissism and self-esteem revisited: The relationships between the subscales of the NPI and explicit/implicit self-esteem. "Polish Psychological Bulletin".

Pincus, A. L., Ansell, E. B., Pimentel, C. A., Cain, N. M., Wright, A. G. C., Levy, K. N. (2009). Initial construction and validation of the Pathological Narcissism Inventory. "Psychological Assessment", 21(3).

Pincus, A. L., Cain, N. M., Wright, A. G. C. (2014). Narcissistic grandiosity and narcissistic vulnerability in psychotherapy. "Personality Disorders: Theory, Research, and Treatment", 5(4).

Pincus, A. L., Lukowitsky, M. R. (2010). Patological narcissism and Narcissistic Personality Disorder. "Annual Reviews of Clinical Psychology”, Vol. 6.

Raskin, R. N., Hall, C. S. (1979). A narcissistic personality inventory. Access on the internet: www.journals.sagepub.com

Ronningstam, E. F. (2005). Identifying and understanding the narcissistic personality. Oxford University Press.

Rosenthal, S. A., Hooley, J. M. (2010). Narcissism assessment in social-personality research: Does the association between narcissism and psychological health result from a confound with self-esteem? "Journal of Research in Personality", 44(4).

Rosenthal, S. A., Pittinsky, T. L. (2006). Narcissistic leadership. “The Leadership Quarterly”, Vol. 17, issue 6.

Vater, A., Schröder-Abé, M., Renneberg, B., Schulze, L., Bosson, J. K., Roepke, S. (2013). The Narcissistic Personality Inventory: a useful tool for assessing pathological narcissism? Evidence from patients with narcissistic personality disorder. "Journal of Personality Assessment", 95(3). 
Watson, D., Gamez, W., Simms, L. J. (2005). Basic dimensions of temperament and their relation to anxiety and depression: A symptom-based perspective. "Journal of Research in Personality", 39.

Wilson, T. D., Lindsey, S., Schooler, T. Y. (2000). A model of dual attitudes. "Psychological Review", Vol. 107(1).

Wright, A. G. C., Lukowitsky, M. R., Pincus, A. L., Conroy, D. E. (2010). The higher order factor structure and gender invariance of the Pathological Narcissism Inventory. "American Psychological Association, Society for Clinical Psychology" (Division 12), Section IX (Assessment,) 20.

Xiao, X., Liu, F., Zhou, F., Chen, S. (2018). Narcissistic leadership and employees' knowledge sharing: Influence of organizational identification and collectivism. "Social Behavior and Personality", 46(8).

Zeigler-Hill, V. (2006). Discrepancies between implicite and explicit self-esteem: Implications for narcissism and self-esteem instability. "Journal of Personality”, Vol. 74, issue 1. Access on the internet: www.onlinelibrary.wiley.com

Zweigenhaft, R. L. I., Marlowe, D. (1973). Signature size: Studies in expressive movement. “Journal of Consulting and Clinical Psychology”, 40.

DOI: $10.7862 /$ rz.2021.hss.27

The text was submitted to the editorial office: December 2021.

The text was accepted for publication: December 2021. 